\title{
Population pharmacokinetics of olprinone in healthy male volunteers
}

This article was published in the following Dove Press journal:

Clinical Pharmacology:Advances and Applications

4 March 2014

Number of times this article has been viewed

\author{
Takayuki Kunisawa' \\ Hidefumi Kasai ${ }^{2}$ \\ Makoto Suda ${ }^{2}$ \\ Manabu Yoshimura ${ }^{3}$ \\ Ami Sugawara ${ }^{3}$ \\ Yuki Izumi ${ }^{3}$ \\ Takafumi lida ${ }^{3}$ \\ Atsushi Kurosawa ${ }^{3}$ \\ Hiroshi Iwasaki ${ }^{3}$ \\ 'Surgical Operation Department, \\ Asahikawa Medical University \\ Hospital, Hokkaido, Japan; ${ }^{2}$ Clinical \\ Study Management Division, Bell \\ Medical Solutions Inc, Tokyo, Japan; \\ ${ }^{3}$ Department of Anesthesiology and \\ Critical Care Medicine, Asahikawa \\ Medical University, Hokkaido, Japan
}

Correspondence: Takayuki Kunisawa Department of Anesthesiology and Critical Care Medicine, Asahikawa Medical University, 2-I-I-I Midorigaoka-higashi, Asahikawa, Hokkaido 078-85 I0, Japan

Tel +8I I66 682583

Fax $+81 \quad 166682589$

Email taka.kunisawa@nifty.ne.jp
Background: Olprinone decreases the cardiac preload and/or afterload because of its vasodilatory effect and increases myocardial contractility by inhibiting phosphodiesterase III.

Purpose: The objective of this study was to characterize the population pharmacokinetics of olprinone after a single continuous infusion in healthy male volunteers.

Methods: We used 500 plasma concentration data points collected from nine healthy male volunteers for the study. The population pharmacokinetic analysis was performed using the nonlinear mixed effect model $\left(\mathrm{NONMEM}^{\circledR}\right)$ software.

Results: The time course of plasma concentration of olprinone was best described using a two-compartment model. The final pharmacokinetic parameters were total clearance $(7.37 \mathrm{~mL} / \mathrm{minute} / \mathrm{kg})$, distribution volume of the central compartment $(134 \mathrm{~mL} / \mathrm{kg})$, intercompartmental clearance $(7.75 \mathrm{~mL} / \mathrm{minute} / \mathrm{kg})$, and distribution volume of the peripheral compartment $(275 \mathrm{~mL} / \mathrm{kg}$ ). The interindividual variability in the total clearance was $12.4 \%$, and the residual error variability (exponential and additive) were $22.2 \%$ and 0.129 (standard deviation). The final pharmacokinetic model was assessed using a bootstrap method and visual predictive check.

Conclusion: We developed a population pharmacokinetic model of olprinone in healthy male adults. The bootstrap method and visual predictive check showed that this model was appropriate. Our results might be used to develop the population pharmacokinetic model in patients.

Keywords: phosphodiesterase III inhibitor, men, pharmacokinetic model

\section{Introduction}

Phosphodiesterase (PDE) III inhibitors induce myocardial contractility and peripheral vasodilation through accumulation of intracellular cyclic adenosine monophosphate (cAMP) in myocardial and vascular smooth muscle cells. ${ }^{1-3}$ PDE III inhibitors increase cAMP levels without activating beta receptors and are thus useful for controlling acute exacerbation of chronic heart failure in patients resistant to catecholamines or those receiving beta blockers. In addition, PDE III inhibitors act without increasing myocardial oxygen consumption. ${ }^{4,5}$ They are commonly used for perioperative circulation management, especially at the time of weaning from cardiopulmonary bypass after procedures such as aortocoronary bypass surgery and mitral valve replacement, which improves peripheral circulation and hemodynamic stability. ${ }^{67}$ However, development of hypotension and arrhythmia after administration of such inhibitors should be carefully monitored. ${ }^{1,7}$ Therefore, PDE III inhibitors are not established as a standard treatment for perioperative circulation management in the current clinical settings. Among PDE III inhibitors, olprinone exerts stronger vasodilatory effects, especially pulmonary vasodilatory effect and reduction in arterial afterload, than milrinone. ${ }^{3,8,9}$ 
Target-controlled infusion (TCI) is an infusion system that allows physicians to adjust the infusion rate by using a pharmacokinetic model and to control drug concentration at the target site. ${ }^{10,11}$ Therefore, TCI of olprinone enables effective and safe administration of olprinone. We performed a population pharmacokinetic analysis to develop a pharmacokinetic model of olprinone by using plasma concentration data obtained from Phase I studies.

\section{Material and methods Subjects and studies}

In this study, we collected 530 plasma concentration data points of olprinone from nine healthy male volunteers (subject numbers 1, 2, 3, 4, 5, 6, 7, 8, and 9; total number of subjects, 39) who participated in two clinical trials (Study I and II, Table 1). Missing data and concentrations below the lower limit of quantitation were excluded from the analysis. These two studies were performed to evaluate the safety, pharmacokinetics, and pharmacological effect after intravenous administration of olprinone. The eligible subjects were healthy adult male volunteers with no clinical abnormality in a medical interview, physical examination, electrocardiogram test, blood pressure measurement, blood test, and urine test. The study protocols were reviewed and approved by the Institutional Review Boards of each clinical study site. Written informed consent was obtained from each subject.

\section{Study design}

This clinical trial was conducted in two separate steps (Table 2). In the first step, seven single doses of olprinone were administered as a 5-minute infusion (Study I).

Table I Cumulative numbers of subjects and background factors

\begin{tabular}{|c|c|c|c|}
\hline & Total & & \\
\hline Number of subjects & 9 & & \\
\hline \multirow[t]{2}{*}{ Number of measurements } & $530(500)^{\mathrm{a}}$ & \multirow{2}{*}{\multicolumn{2}{|c|}{ Studv II }} \\
\hline & Study I & & \\
\hline Total number of subjects & $27(26)^{a}$ & $12(11)^{\mathrm{a}}$ & \\
\hline \multirow[t]{2}{*}{ Number of measurements } & $312(300)^{\mathrm{a}}$ & $218(200)^{\mathrm{a}}$ & \\
\hline & $\begin{array}{l}\text { Age } \\
\text { (years) }\end{array}$ & $\begin{array}{l}\text { Height } \\
(\mathrm{cm})\end{array}$ & $\begin{array}{l}\text { Body } \\
\text { weight (kg) }\end{array}$ \\
\hline Mean & 27.2 & 171.5 & 64.1 \\
\hline Standard deviation & 2.8 & 4.4 & 6.9 \\
\hline Median & 26.0 & 173.0 & 61.5 \\
\hline Minimum & 24.0 & 163.2 & 56.5 \\
\hline Maximum & 32.0 & 177.6 & 75.0 \\
\hline
\end{tabular}

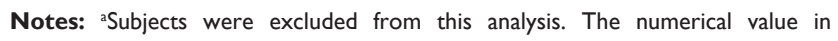
parentheses shows the numbers after exclusion of these data.
Table 2 Study design

\begin{tabular}{|c|c|c|c|c|}
\hline Stage & Dose $(\mu \mathrm{g} / \mathrm{kg})$ & Group & $\begin{array}{l}\text { Subjects } \\
\text { (n) }\end{array}$ & $\begin{array}{l}\text { Subject } \\
\text { numbers }\end{array}$ \\
\hline \multicolumn{5}{|l|}{ Study I } \\
\hline I & 5.0 & $A$ & 4 & $\mathrm{I}, 2,3$, and 4 \\
\hline II & 10.0 & B & 4 & $5,6,7$, and 8 \\
\hline III & 2.5 & B & 4 & $5,6,7$, and 8 \\
\hline IV & 20.0 & $A$ & 4 & $\mathrm{I}, 2$, 3 , and 4 \\
\hline V & 30.0 & B & 4 & $5,6,7$, and 8 \\
\hline VI & 1.25 & C & 6 & $\mathrm{I}, 5$, and 9 \\
\hline VII & 50.0 & A & 4 & $\mathrm{I}, 2,3$, and 4 \\
\hline \multicolumn{5}{|c|}{ Study II } \\
\hline VIII & $\begin{array}{l}61.25 \text { (loading dose, } \\
20 \mu \mathrm{g} / \mathrm{kg} \text {; continuous } \\
\text { infusion rate, } \\
0.25 \mu \mathrm{g} / \mathrm{kg} / \mathrm{min} \text { ) }\end{array}$ & B & 4 & $5,6,7$, and 8 \\
\hline IX & $\begin{array}{l}\text { I22.50 (loading } \\
\text { dose, } 40 \mu \mathrm{g} / \mathrm{kg} \text {; } \\
\text { continuous infusion } \\
\text { rate, } 0.5 \mu \mathrm{g} / \mathrm{kg} / \mathrm{min} \text { ) }\end{array}$ & A & 4 & $\mathrm{I}, 2,3$, and 9 \\
\hline$x$ & $\begin{array}{l}\text { I } 63.75 \text { (loading } \\
\text { dose, } 40 \mu \mathrm{g} / \mathrm{kg} \text {; } \\
\text { continuous infusion } \\
\text { rate, } 0.75 \mu \mathrm{g} / \mathrm{kg} / \mathrm{min} \text { ) }\end{array}$ & $\mathrm{B}^{\prime b}$ & 4 & $\mathrm{I}, 5, \mathrm{c} 6$, and 7 \\
\hline
\end{tabular}

Notes: Subjects in Stages I to VII received a 5-minute infusion. The group receiving $1.25 \mu \mathrm{g} / \mathrm{kg}$ consisted of 6 subjects. The subjects were randomly divided into subgroups with three subjects in each subgroup. To compare the occurrence of hyperemia between the subgroups, three subjects were administered olprinone, and the other three were administered the placebo. Subjects in Stages VIII to $X$ received a single 3-hour infusion. 'Subject was excluded from the analysis; ' $B$ ' group: one subject in the $B$ group was replaced with a subject in the $A$ group; 'subject was excluded from the analysis.

After Study I, three doses were administered as a 3-hour infusion combination of a 165-minute maintenance infusion following a 15-minute loading dose (Study II). Each stage comprised four evaluation periods as follows: 1 ) a screening period; 2) a baseline period, a 24-hour period before the start of the study treatment period, during which baseline evaluations were made; 3 ) a study treatment period, 24 hours after drug administration; and 4) a follow-up period, 7 days after drug administration. The intervals between administrations were at least 7 days.

\section{Study I}

We randomized eight subjects to the two treatment groups (Group A and Group B). Subjects in Group A (subject numbers $1,2,3$, and 4 ) received 5,20 , and $50 \mu \mathrm{g} / \mathrm{kg}$ olprinone as a single continuous infusion over 5 minutes. Subjects in Group B (subject numbers 5, 6, 7, and 8) received 2.5, 10, and $30 \mu \mathrm{g} / \mathrm{kg}$ olprinone as a single continuous infusion over 5 minutes. In addition, six subjects (Group C), including five who participated in Study I, were randomized in a doubleblind, manner to the either the $1.25 \mu \mathrm{g} / \mathrm{kg}$ olprinone (subject numbers 1, 5, and 9) or placebo subgroup. The treatments 
were administered to each of the three subjects over 5 minutes. We collected $5 \mathrm{~mL}$ venous blood samples from each subject before the administration; at 5, 7.5, 10, 15, 30, and 45 minutes; and at 1, 1.5, 2, 3, 4, 6, 8, and 24 hours after the administration to measure the plasma concentration of olprinone.

\section{Study II}

Subjects in Group B (subject numbers 5, 6, 7, and 8) received a loading dose at a rate of $1.33 \mu \mathrm{g} / \mathrm{kg} /$ minute for 15 minutes followed by continuous infusion at a rate of $0.25 \mu \mathrm{g} / \mathrm{kg} / \mathrm{minute}$ for 165 minutes; subjects in Group A (subject numbers 1, 2, 3, and 9) received a loading dose at a rate of $2.67 \mu \mathrm{g} / \mathrm{kg} /$ minute for 15 minutes followed by continuous infusion at a $0.5 \mu \mathrm{g} / \mathrm{kg} /$ minute for 165 minutes; and subjects in Group B' (subject numbers 1, 5, 6, and 7) received a loading dose at a rate of $2.67 \mu \mathrm{g} / \mathrm{kg} / \mathrm{minute}$ for 15 minutes followed by continuous infusion at a rate of $0.75 \mu \mathrm{g} / \mathrm{kg} /$ minute for 165 minutes. Group B' consists of three subjects from Group B and one subject from Group A of Study I. Group A consists of three subjects from Group A of Study I and a newly enrolled subject from Group C of Study I. We collected $5 \mathrm{~mL}$ venous blood samples from each subject before the administration, at 15 and 30 minutes, and at 1, 2, 3, 3.04, 3.08, 3.16, 3.25, 3.5, 4, $4.5,5,6,7,9,11$, and 24 hours after the administration to measure the plasma concentration of olprinone.

\section{Plasma concentration of olprinone}

The concentrations of unchanged olprinone in the plasma were measured using a sensitive and specific highperformance liquid chromatography (HPLC) method. To each $1 \mathrm{~mL}$ of plasma, $100 \mu \mathrm{L}$ of internal standard solution (milrinone $10 \mathrm{ng} / 100 \mu \mathrm{L}$ methanol) and $1 \mathrm{~mL}$ of $0.2 \mathrm{M}$ phosphate buffer solution ( $\mathrm{pH}$ 5.5) were added and mixed on a vortex mixer. The mixture was applied on the top of a Bond Elut $\mathrm{C} 18^{\circledR}$ column (Analytichem International, Harbor City, CA, USA). After washing the column with $2 \mathrm{~mL} \mathrm{H}_{2} \mathrm{O}$ and $2 \mathrm{~mL}$ $\mathrm{H}_{2} \mathrm{O}$ containing $10 \%$ methanol, olprinone was eluted twice with $0.5 \mathrm{~mL}$ of methanol, and the effluent was evaporated to dryness at $50^{\circ} \mathrm{C}$ under a gentle stream of nitrogen gas. Then the dried residue was dissolved in $100 \mu \mathrm{L}$ of methanol and a $50 \mu \mathrm{L}$ portion was injected onto the HPLC column. The quantification limit was $0.1 \mathrm{ng} / \mathrm{mL}$.

This analytical method was validated for selectivity (no peak interfering with peak of olprinone), linearity ( $r=0.999)$, precision (intraday assay, $1.25 \%$ to $9.79 \%, \mathrm{n}=4$; interday assay, $3.24 \%$ at $4.90 \mathrm{ng} / \mathrm{mL}, \mathrm{n}=3$ ), recovery ( $89.2 \%$ to $125.1 \%$ in $0.1-10 \mathrm{ng} / \mathrm{mL}, 92.5 \%$ to $107.3 \%$ in $10-100 \mathrm{ng} / \mathrm{mL}$ ), and calibration curve $(0.1-100 \mathrm{ng} / \mathrm{mL})$.

\section{Development of a population pharmacokinetic model for olprinone}

The population pharmacokinetic analysis of olprinone was performed using the nonlinear mixed effect model (NONMEM $^{\circledR}$; ICON Development Solutions, Ellicott City, MD, USA) software package, version 7.2.0, with the PREDPP subroutines (ADVAN1, ADVAN3, or ADVAN11). The firstorder conditional estimation with interaction method was used for estimation of the parameters. Bootstrap resampling was performed using the MULTTEST procedure of the SAS ${ }^{\circledR}$ 9.2 software (SAS Institute Inc, Cary, NC, USA).

We fitted one-, two-, or three-compartment models to the data when selecting the basic structural model. We examined the interindividual variability for all pharmacokinetic parameters. The interindividual variability was calculated using an exponential error model. The residual variability was determined by using an exponential error model or a mixed error model. Dose and all pharmacokinetic parameters such as total clearance (CL), distribution volume of the central compartment (V1), intercompartmental clearance (Q or Q2 and Q3) and distribution volume of the peripheral compartment (V2 and V3) were adjusted for body weight. The model was selected by statistical evaluation of the objective function value difference $(\triangle \mathrm{OBJ})$ using $\chi^{2}$-test, goodness of fit plots, and $95 \%$ confidence interval of parameter estimates. The $95 \%$ confidence interval of parameter estimate was calculated using the point estimate $\pm 1.96 \times$ standard error $(\mathrm{SE})$, which was taken from the covariance step. Coefficient of variation (CV) or standard deviation (SD) of interindividual variability and residual error variability were calculated from square root of variance estimate. The significance level for the forward selection step and backward elimination step were 0.05 $(\triangle \mathrm{OBJ}<3.84)$ and $0.01(\Delta \mathrm{OBJ}<6.63)$, respectively.

Age as a covariate candidate was tested using the following formula:

$$
P i=P+\theta_{B G} \times B G
$$

where $P i$ denotes the pharmacokinetic parameter estimates of subject $i, P$ denotes the population estimates of the pharmacokinetic parameter, $B G$ denotes the background factor of subjects, and $\theta_{B G}$ denotes the impact of background factor. The linear relation model was used because the range of the background factor was too narrow to use other models.

\section{Model validation}

The bootstrap method was used to evaluate the robustness and stability of the final model. ${ }^{12}$ One thousand bootstrap data sets 
were reconstructed by resampling the subjects from the original data set. The mean and SD of parameter estimates obtained from the bootstrap replications were compared to the final parameter estimates and SE obtained from the original data set. Successful run in NONMEM was defined as normal completion of both estimation and covariance steps. Moreover, a visual predictive check (VPC) was used to assess the final model.

\section{Results}

\section{Subjects}

The demographic factors of the subject are summarized in Table 1. Nine subjects participated in this study. The total number of subjects in Study I was 27, and in Study II was 12. We collected 312 plasma concentration data points in Study I and 218 in Study II. Summary statistics (mean \pm SD) of age, height and body weight were $27.2 \pm 2.8$ years, $171.5 \pm 4.4 \mathrm{~cm}$, and $64.1 \pm 6.9 \mathrm{~kg}$, respectively.

Plasma concentration-time profiles of olprinone for each dose $(5,10$, and $2.5 \mu \mathrm{g} / \mathrm{kg}$ in Study I) are shown in Figure 1. Plasma concentration of olprinone rapidly decreased after termination of the continuous infusion. In subject numbers 2 and 5 , plasma concentrations of olprinone were 0 at 1,440 minutes in the prior stage, and the dose intervals to the next stage were more than 7 days. Olprinone $(0.053 \mathrm{ng} / \mathrm{mL}$ and $2.002 \mathrm{ng} / \mathrm{mL})$ was detected in the plasma of subject numbers 2 and 5 before the administration. Therefore, these data (number 2 in Stage IV and number 5 in Stage $\mathrm{X}$ ) were excluded from this analysis.

\section{Selection of the base model of population pharmacokinetic model}

The OBJ of one-, two-, and three-compartment models were $2,762.341,1,835.064$, and 1,268.120, respectively. The three-compartment model showed minimum OBJ. Generally, the OBJ decreases with an increase in the number of compartments. In the three-compartment model, the estimates of Q3 $(0.174 \mathrm{~mL} / \mathrm{minute} / \mathrm{kg})$ and V3 $(79.5 \mathrm{~mL} / \mathrm{kg})$ were smaller than the other estimates (CL, $7.34 \mathrm{~mL} / \mathrm{minute} / \mathrm{kg}$ and $\mathrm{V} 1,125 \mathrm{~mL} / \mathrm{kg}$; Q2, $8.74 \mathrm{~mL} / \mathrm{minute} / \mathrm{kg}$ and V2, $260 \mathrm{~mL} / \mathrm{kg}$ ), which indicated a minimum and clinically negligible effect of the third compartment on the time-concentration curve. Thus, we selected the two-compartment model, and the concentrations predicted using this model were mostly fitted to the observed data (Figure 2). Then, the residual error variability was used for a mixed error model (exponential and

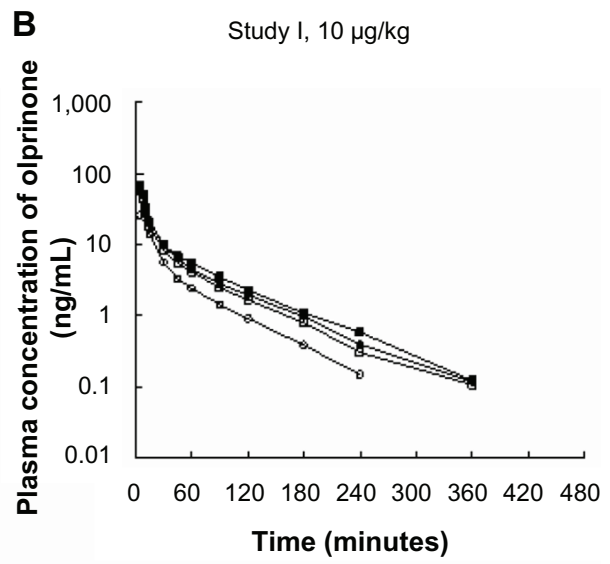

Figure I Plasma concentration-time profiles of different doses of olprinone (A-C).

Notes: (A) $\bigcirc$ Subject I, $\bullet$ Subject 2, $\square$ Subject 3, $\square$ Subject 4. (B) $\bigcirc$ Subject 5 , $\bullet$ Subject 6, $\square$ Subject 7, $\square$ Subject 8 . (C) $\bigcirc$ Subject 5, $\bullet$ Subject 6, $\square$ Subject 7, $\square$ Subject 8 .
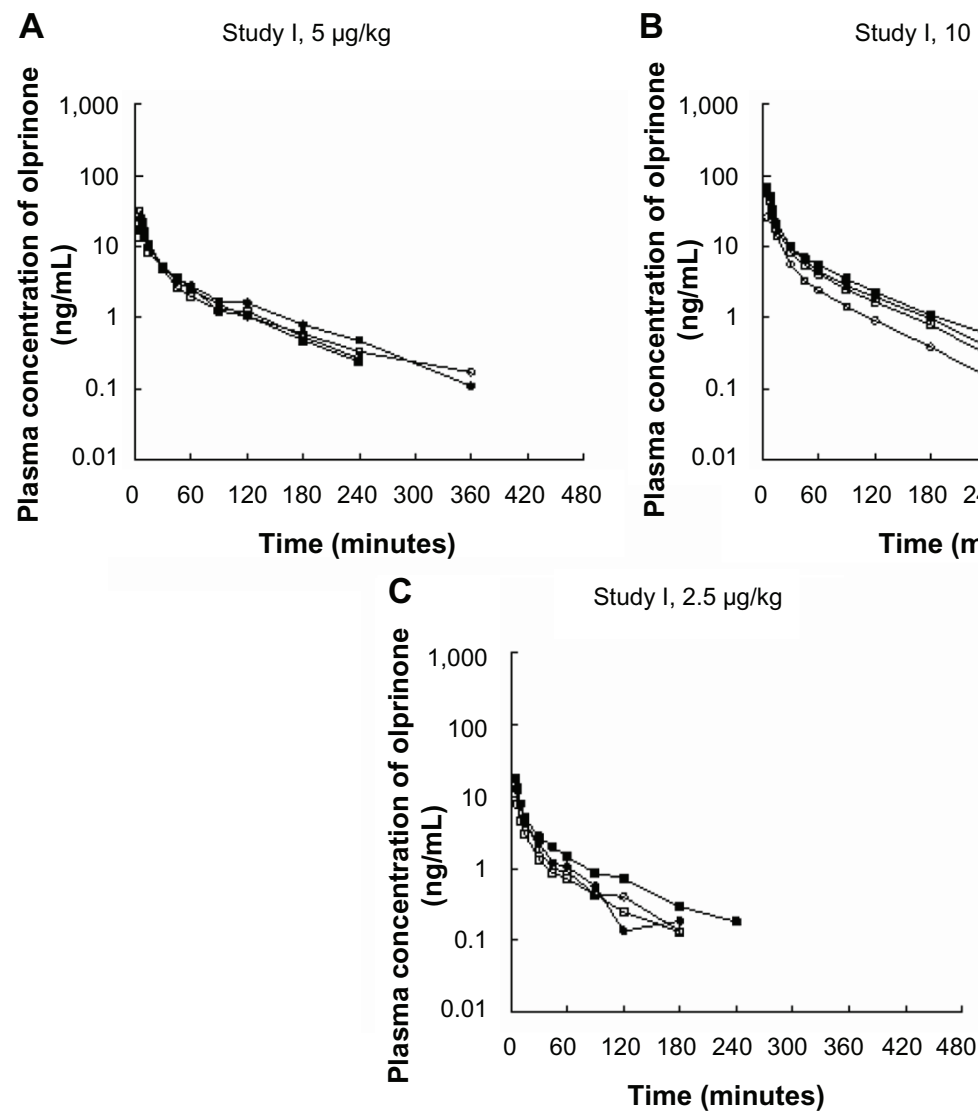
A

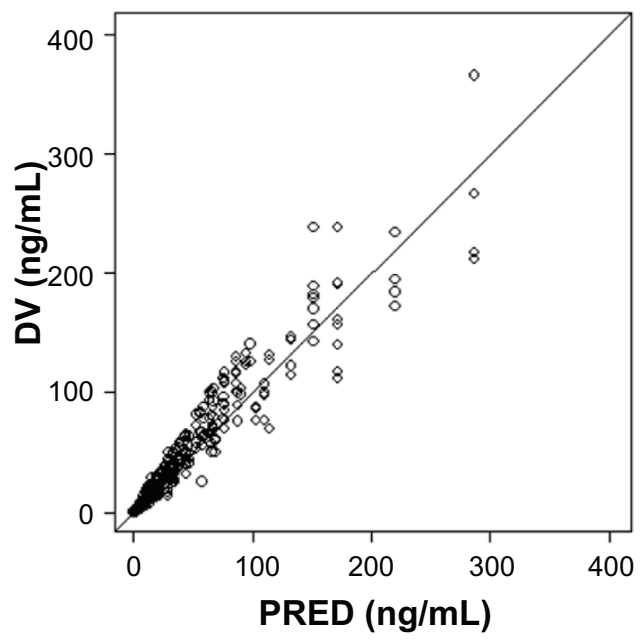

B

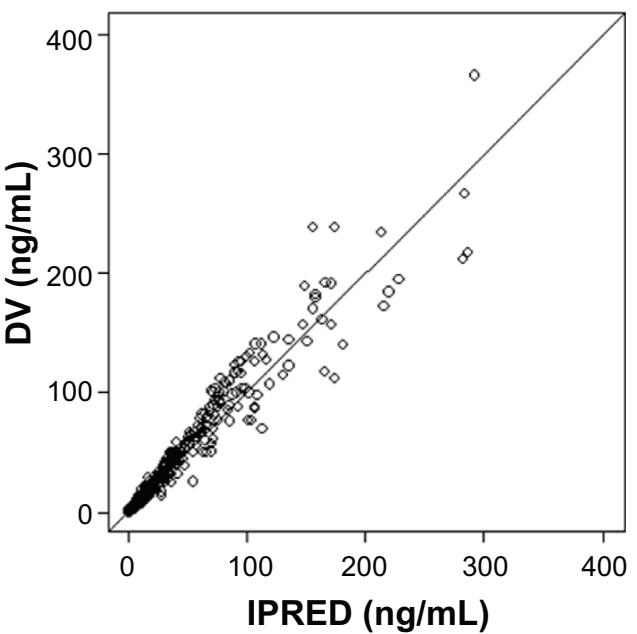

Figure 2 Goodness-of-fit plots (PRED versus DV, IPRED versus DV) for the final model.

Notes: (A) Observed plasma concentration of olprinone versus predicted values. (B) Observed plasma concentration of olprinone versus individual predicted values. Abbreviations: DV, observed plasma concentration of olprinone; IPRED, individual predicted values; PRED, predicted values.

additive model) (OBJ, 1,323.213). Therefore, the twocompartment model with the interindividual variability on CL was selected as a base model.

\section{Selection of the final population pharmacokinetic model}

Correlation coefficient between the post hoc estimate of pharmacokinetic parameter (CL), which was obtained from the base model, and the background factor of subjects (age) was 0.240 . In the forward selection step, age was not included as covariate on $\mathrm{CL}$ in the pharmacokinetic model $(P=0.363)$. The final model was therefore identical with the base model.

\section{Model evaluation}

Pharmacokinetic parameters from the final model are shown in Table 3. Estimates of CL, V1, Q, and V2 were

Table 3 Population pharmacokinetic parameter estimates from the final model

\begin{tabular}{lcll}
\hline & Mean \pm SD & $\% C V$ & $\begin{array}{l}\text { 95\% confidence } \\
\text { interval }\end{array}$ \\
\hline $\mathrm{CL}(\mathrm{mL} / \mathrm{min} / \mathrm{kg})$ & $7.37 \pm 0.376$ & & $6.63-8.1 \mathrm{I}$ \\
$\mathrm{VI}(\mathrm{mL} / \mathrm{kg})$ & $134 \pm 9.5 \mathrm{I}$ & & $115-153$ \\
$\mathrm{Q}(\mathrm{mL} / \mathrm{min} / \mathrm{kg})$ & $7.75 \pm 0.538$ & & $6.70-8.80$ \\
$\mathrm{~V} 2(\mathrm{~mL} / \mathrm{kg})$ & $275 \pm 9.97$ & & $255-295$ \\
$\omega_{\mathrm{CL}}{ }^{2}$ & $0.0153 \pm 0.00557$ & 12.4 & $0.00438-0.0262$ \\
$\sigma_{\text {exponential }}^{2}$ & $0.0495 \pm 0.00548$ & 22.2 & $0.0388-0.0602$ \\
$\sigma_{\text {additive }}^{2}$ & $0.0166 \pm 0.00599$ & $0.129(\mathrm{SD})$ & $0.00486-0.0283$ \\
\hline
\end{tabular}

Abbreviations: $\omega^{2}$, variance for interindividual variability; $\sigma^{2}$, variance for intraindividual variability; \%CV, coefficient of variance; $\mathrm{CL}$, total clearance; $\mathrm{Q}$, intercompartmental clearance; SD, standard deviation; VI, distribution volume of the central compartment; V2, distribution volume of the peripheral compartment.
$7.37 \mathrm{~mL} /$ minute $/ \mathrm{kg}, 134 \mathrm{~mL} / \mathrm{kg}, 7.75 \mathrm{~mL} /$ minute $/ \mathrm{kg}$, and $275 \mathrm{~mL} / \mathrm{kg}$, respectively. The $\mathrm{CV}$ of the interindividual variability on the $\mathrm{CL}$ was $12.4 \%$, and the residual error variability (exponential and additive) was $22.2 \%$ and 0.129 (SD). The relationships between the observed values and predicted values (PRED) or individual predicted values of the final model are shown in Figure 2. The relationships between conditional weighted residuals ${ }^{13}$ and time or PRED of the final model are shown in Figure 3. The PRED obtained from the final model well described the observed data.

\section{Model validation}

The results of the bootstrap validation are shown in Table 4 . The success rate was $99.3 \%$, and the parameter estimates and SD of the final model were consistent with those of the bootstrap, which suggested good robustness and stability of the final model. Furthermore, the result of VPC is shown in Figure 4 . The distribution of predictions simulated from the final model fitted well with those of the observations.

\section{Discussion}

We constructed a population pharmacokinetics model with full sampling data (average 13.6 points per subject) using nine healthy male volunteers. Tsubokawa et $\mathrm{al}^{14}$ reported a population pharmacokinetics model for olprinone using 26 patients undergoing cardiac surgery with cardiopulmonary bypass. In this study, the plasma concentration of olprinone was best described using a two-compartment model. The half-life of olprinone in the alpha and beta phases was 5.4 and 57.7 minutes, respectively. Tsubokawa et a $1^{14}$ 
A
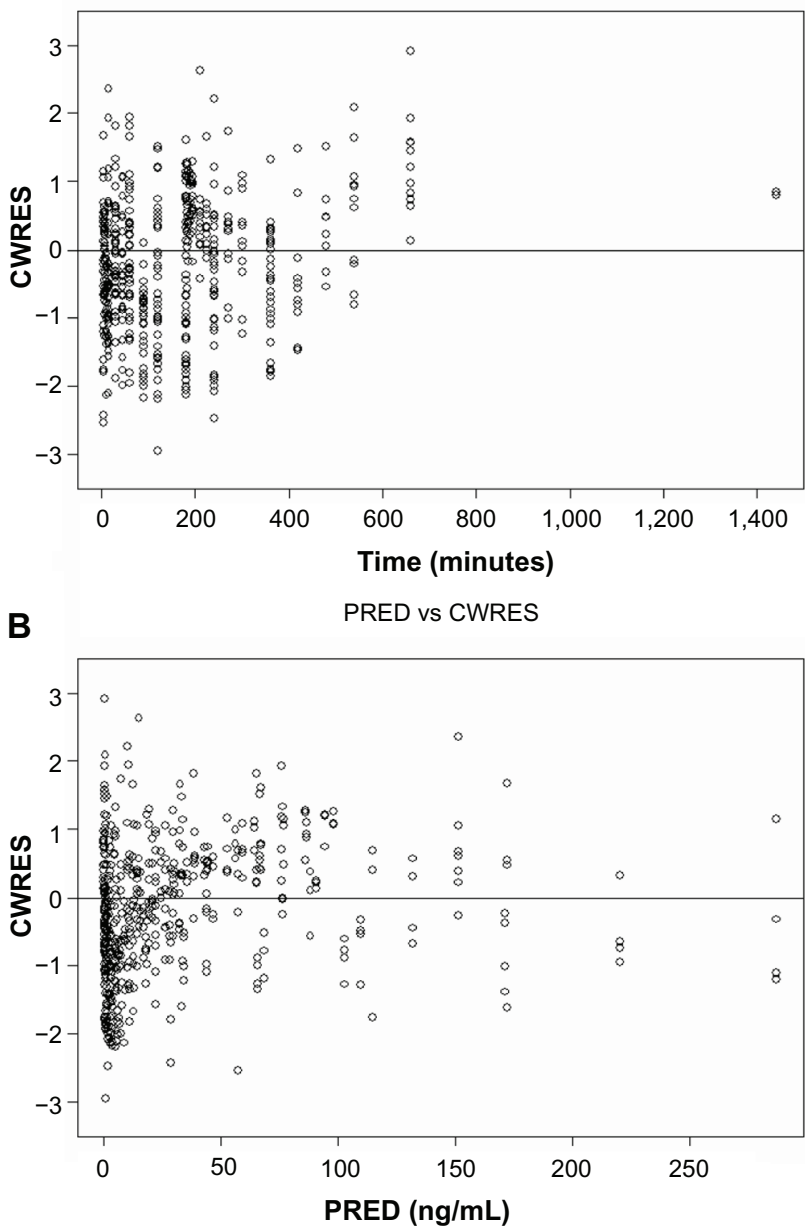

Figure 3 Goodness-of-fit plots (TIME versus CWRES, PRED versus CWRES) for the final model.

Notes: (A) Conditional weighted residuals versus time. (B) Conditional weighted residuals versus the predicted values.

Abbreviations: CWRES, conditional weighted residuals; PRED, predicted values.

Table 4 Results of bootstrap analysis

\begin{tabular}{|c|c|c|c|}
\hline \multirow{3}{*}{$\begin{array}{l}\begin{array}{l}\text { Successful } \\
\text { run }^{\mathrm{a}}\end{array} \\
\text { Parameter }\end{array}$} & \multicolumn{3}{|l|}{993} \\
\hline & \multirow{2}{*}{$\begin{array}{l}\text { Final model } \\
\text { Mean } \pm \text { SE }\end{array}$} & \multicolumn{2}{|l|}{ Bootstrap } \\
\hline & & Mean \pm SD & $\begin{array}{l}95 \% \text { confidence } \\
\text { interval }\end{array}$ \\
\hline $\mathrm{CL}$ & $7.37 \pm 0.376$ & $7.39 \pm 0.376$ & $6.70-8.17$ \\
\hline VI & $|34 \pm 9.5|$ & $134 \pm 9.26$ & $117-154$ \\
\hline $\mathrm{Q}$ & $7.75 \pm 0.538$ & $7.74 \pm 0.552$ & $6.64-8.88$ \\
\hline V2 & $275 \pm 9.97$ & $275 \pm 10.5$ & $25 I-294$ \\
\hline$\omega_{\mathrm{CL}^{2}}{ }^{2}$ & $0.0153 \pm 0.00557$ & $0.0139 \pm 0.00539$ & $0.00486-0.0245$ \\
\hline$\sigma_{\text {expon }}^{2}$ & $0.0495 \pm 0.00548$ & $0.0491 \pm 0.00559$ & $0.0373-0.0592$ \\
\hline$\sigma_{\text {additive }}^{2}$ & $0.0166 \pm 0.00599$ & $0.0169 \pm 0.00618$ & $0.0077|-0.032|$ \\
\hline
\end{tabular}

Notes: ${ }^{\mathrm{a}} \mathrm{A}$ successful run was defined as the number of normal completions of both the estimation step and covariance step of nonlinear mixed effect model among I,000 repeated analyses. Two runs failed at the estimation step.

Abbreviations: $\omega^{2}$, variance for interindividual variability; $\sigma^{2}$, variance for intraindividual variability; CL, total clearance; $\mathrm{Q}$, intercompartmental clearance; SD, standard deviation; SE, standard error; VI, distribution volume of the central compartment; V2, distribution volume of the peripheral compartment.
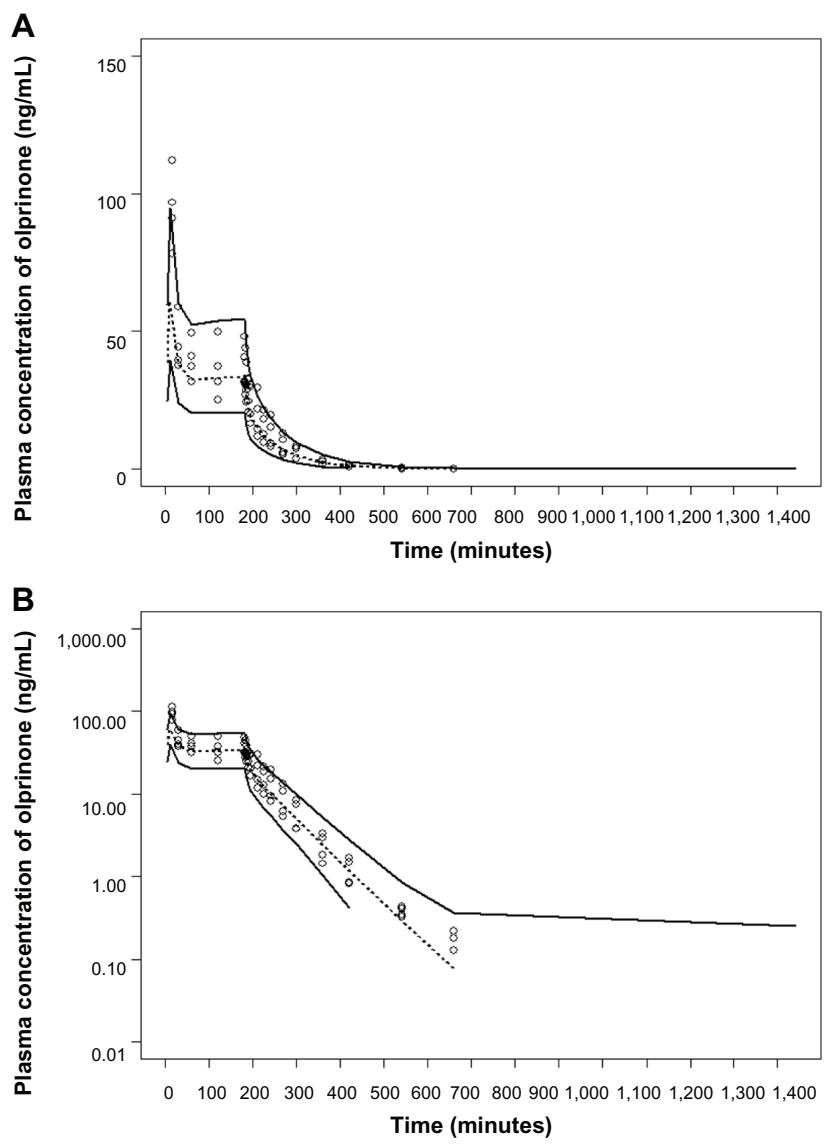

Figure 4 Visual predictive check in the final model for olprinone (Stage VIII, a loading dose at a rate of $1.33 \mu \mathrm{g} / \mathrm{kg} /$ minute for 15 minutes followed by continuous infusion at a rate of $0.25 \mu \mathrm{g} / \mathrm{kg} /$ minute for 165 minutes).

Notes: (A) Linear plot; (B) semi-log plot. Open circles represent the data observed. Solid lines represent the 97.5 th percentile and 2.5 th percentile of the prediction interval. The dotted line represents the 50 th percentile of the prediction interval.

reported that $\mathrm{CL}, \mathrm{V} 1$, and half-life were $7.13 \mathrm{~mL} /$ minute $/ \mathrm{kg}$, $802 \mathrm{~mL} / \mathrm{kg}$, and 97.1 minutes, respectively. The half-life of olprinone in the beta phase in our study was shorter than that reported previously. Kimata et al ${ }^{3}$ reported a positive correlation between the serum creatinine clearance and elimination half-life of olprinone. Tsubokawa et $\mathrm{al}^{14}$ reported a mean creatinine clearance of $57 \mathrm{~mL} /$ minute, which was lower than the creatinine clearance in healthy male volunteers. Therefore, the difference in half-life was attributed to renal function.

Clinical application of TCI infusion for drugs commonly used for anesthesia such as propofol, ${ }^{15,16}$ remifentanil, ${ }^{17}$ and rocuronium ${ }^{18}$ has been reported previously. However, to date, no study has described the clinical application of TCI infusion for PDE III inhibitors such as olprinone and milrinone.

Olprinone is metabolized as a glucuronate conjugate in the liver. The plasma concentrations of olprinone that exert vasodilatory or cardiotonic effects in the extracted radial artery sections are $0.107 \mu \mathrm{mol} / \mathrm{L}(32.6 \mathrm{ng} / \mathrm{mL})$ or $0.35 \mu \mathrm{mol} / \mathrm{L}$ 
(106.7 ng/mL), respectively. ${ }^{9,19}$ However, in the study by Arai et $\mathrm{al}^{20}$ on off-pump coronary artery bypass, the blood concentration of olprinone 2 hours after administration at $0.2 \mu \mathrm{g} / \mathrm{kg} / \mathrm{minute}$ was $27 \mathrm{ng} / \mathrm{mL}$. Subsequently, olprinone was administered at an infusion rate of $0.1 \mu \mathrm{g} / \mathrm{kg} /$ minute, and the blood concentration was maintained over $15 \mathrm{ng} / \mathrm{mL}$ for 3 hours after returning to the ICU. Compared to the cardiac index after induction of anesthesia, that for 3 hours after returning to the ICU significantly increased. ${ }^{20}$ Currently, PDE III inhibitors are not used as standard agents in perioperative circulation management because of the possibility of development of adverse reactions such as hypotension and arrhythmia. After establishing the TCI infusion system, PDE III inhibitors may be used as standard agents in perioperative circulation management. The TCI infusion system may be used in the same manner as the drugs such as propofol and remifentanil in the future; however, this system has not been validated for other drugs thus far. Further studies are required to develop a TCI system for olprinone.

Our results showed that no background factors affected the pharmacokinetics of olprinone. However, our study included a limited number of subjects, limited study population, and limited range of covariates (age). Therefore, our results are not sufficient to conclude that no covariate affected the pharmacokinetics of olprinone. Further studies in patients are required to discuss the pharmacokinetics of olprinone.

\section{Conclusion}

We developed a population pharmacokinetic model of olprinone in healthy male volunteers. The final model was found to be appropriate using a bootstrap method and VPC. However, our study had limitations such as a small number of subjects, limited study population, and limited range of covariates. Thus, further studies in patients are required to determine the pharmacokinetics of olprinone. Our results might be useful to develop a population pharmacokinetic model in patients.

\section{Acknowledgments}

This study was sponsored by Eisai Co, Ltd (Tokyo, Japan).

\section{Disclosure}

The authors declare no conflict of interest in this work.

\section{References}

1. Honerjäger P. Pharmacology of bipyridine phosphodiesterase III inhibitors. Am Heart J. 1991;121(6 Pt 2):1939-1944.
2. Skoyles JR, Sherry KM. Pharmacology, mechanisms of action and uses of selective phosphodiesterase inhibitors. Br J Anaesth. 1992;68(3):293-302.

3. Kimata S, Hirosawa K, Kasanuki H, et al. [Clinical evaluation of E-1020 injection for acute heart failure. Study of acute effects by single intravenous infusion and intravenous drip]. Jpn Clin Exp Med. 1992;69(7): 2260-2274. Japanese.

4. Monrad ES, Baim DS, Smith HS, Lanoue AS. Milrinone, dobutamine, and nitroprusside: comparative effects on hemodynamics and myocardial energetics in patients with severe congestive heart failure. Circulation. 1986;73(3 Pt 2):III168-III174.

5. Adachi $\mathrm{H}$, Tanaka $\mathrm{H}$. Effects of a new cardiotonic phosphodiesterase III inhibitor, olprinone, on cardiohemodynamics and plasma hormones in conscious pigs with heart failure. $J$ Cardiovasc Pharmacol. 1997;29(6):763-771.

6. Rathmell JP, Prielipp RC, Butterworth JF, et al. A multicenter, randomized, blind comparison of amrinone with milrinone after elective cardiac surgery. Anesth Analg. 1998;86(4):683-690.

7. Orime $\mathrm{Y}$, Shiono M, Hata $\mathrm{H}$, et al. Effects of phosphodiesterase inhibitors after coronary artery bypass grafting. Jpn Circ J. 1999;63(2): $117-122$.

8. Takaoka H, Takeuchi M, Odake M, et al. Comparison of the effects on arterial-ventricular coupling between phosphodiesterase inhibitor and dobutamine in the diseases human heart. $J$ Am Coll Cardiol. 1993;22(2):598-606.

9. Adachi H, Kamata S, Kodama K, Nagakura T. Vasorelaxant effect of a phosphodiesterase 3 inhibitor, olprinone, on isolated human radial artery. Eur J Pharmacol. 2000;396(1):43-47.

10. Guarracino F, Lapolla F, Cariello C, et al. Target controlled infusion: TCI. Minerva Anestesiol. 2005;71(6):335-337.

11. Short TG, Lim TA, Tam YH. Prospective evaluation of pharmacokinetic model-controlled infusion of propofol in adult patients. Br J Anaesth. 1996;76(2):313-315.

12. Guidance for industry: population pharmacokinetics. Silver Spring: United States Food and Drug Administration [updated 1999 Feb 1]. Available from: http://www.fda.gov/downloads/Drugs/ GuidanceComplianceRegulatoryInformation/Guidances/UCM072137. pdf. Accessed October 21, 2013.

13. Hooker AC, Staatz CE, Karlsson MO. Conditional weighted residuals (CWRES): a model diagnostic for the FOCE method. Pharm Res. 2007;24(12):2187-2197.

14. Tsubokawa T, Ishizuka S, Fukumoto K, Ueno K, Yamamoto K. Population pharmacokinetics of olprinone in patients undergoing cardiac surgery with cardiopulmonary bypass. J Anesth. 2013;27(2): 243-250.

15. Wietasch JK, Scholz M, Zinserling J, et al. The performance of a target-controlled infusion of propofol in combination with remifentanil: a clinical investigation with two propofol formulations. Anesth Analg. 2006;102(2):430-437.

16. Passot S, Servin F, Allary R, et al. Target-controlled versus manuallycontrolled infusion of propofol for direct laryngoscopy and bronchoscopy. Anesth Analg. 2002;94(5):1212-1216, table of contents.

17. De Castro V, Godet G, Mencia G, Raux M, Coriat P. Target-controlled infusion for remifentanil in vascular patients improves hemodynamics and decreases remifentanil requirement. Anesth Analg. 2003;96(1): 33-38.

18. Vermeyen KM, Hoffmann VL, Saldien V. Target controlled infusion of rocuronium: analysis of effect data to select a pharmacokinetic model. Br J Anaesth. 2003;90(2):183-188.

19. Sugioka M, Ito M, Masuoka H, et al. Identification and characterization of isoenzymes of cyclic nucleotide phosphodiesterase in human kidney and heart, and the effects of new cardiotonic agents on these isoenzymes. Naunyn Schmiedebergs Arch Pharmacol. 1994;350(3):284-293.

20. Arai T, Kamishima K, Terauchi T, et al. [Effects of olprinone hydrochloride in patients undergoing off-pump coronary artery bypass grafting]. Masui. 2006;55(2):158-163. Japanese. 


\section{Publish your work in this journal}

Clinical Pharmacology: Advances and Applications is an international, Visit http://www.dovepress.com/testimonials.php to read real quotes peer-reviewed, open access journal publishing original research, reports,

reviews and commentaries on all areas of drug experience in humans.

The manuscript management system is completely online and includes

a very quick and fair peer-review system, which is all easy to use.

from published authors.

Submit your manuscript here: http://www.dovepress.com/clinical-pharmacology-advances-and-applications-journal 